\title{
Impacts of climate change on electric power supply in the Western United States
}

\author{
Nature Climate Change, 2015, 4(8), pp. 748-752 \\ http://dx.doi.org/10.1038/nclimate2648
}

\author{
Matthew D. Bartos* \\ Research Scientist \\ Civil, Environmental, \& Sustainable Engineering, Arizona State University \\ matthew.d.bartos@gmail.com \\ Phone: (480) 707-8313 \\ FAX: N/A \\ Mikhail V. Chester \\ Assistant Professor \\ Civil, Environmental, \& Sustainable Engineering, Arizona State University \\ mchester@asu.edu \\ Phone: (480) 965-9779 \\ 660 S. College Ave., \\ Tempe, AZ 85287-3005 \\ * Author to whom correspondence should be addressed
}


Climate change may constrain future electricity generation capacity by increasing the incidence of extreme heat and drought events. We estimate reductions to generating capacity in the Western United States based on long-term changes in streamflow, air temperature, water temperature, humidity and air density. We simulate these key parameters over the next half century by joining downscaled climate forcings with a hydrologic modeling system. For vulnerable power stations (46\% of existing capacity), climate change may reduce average summertime generating capacity by 1.1-3.0\%, with reductions of up to $\mathbf{7 . 2 - 8 . 8 \%}$ under a ten-year drought. Currently, power providers do not account for climate impacts in their development plans, meaning that they could be overestimating their ability to meet future electricity needs.

Electric power generation can be disrupted by adverse climatic conditions. Although vulnerabilities are specific to each generation technology, capacity reductions are most likely to occur during extreme heat and drought events ${ }^{1-4}$. During drought conditions, when streamflow is low and temperatures are high, "base-load" coal and nuclear power plants may lack the necessary cooling water to generate at full capacity ${ }^{1,5}$. Insufficient streamflow can also limit electricity production at hydroelectric dams ${ }^{2}$. Peaking technologies - like gas turbines ${ }^{4}$, solar cells ${ }^{6}$, and wind turbines ${ }^{7}$ - are vulnerable to acute changes in atmospheric parameters like air temperature. Drought- and heat-related capacity reductions are especially problematic, because they are likely to occur during periods of high electricity demand ${ }^{3,4}$. From 2001 to 2008, a series of droughts caused electricity shortages in the American Southeast ${ }^{8}$, the Pacific Northwest ${ }^{9}$, and continental Europe $^{10}$. As concentrations of atmospheric carbon increase, drought events are anticipated to increase in frequency, duration, and intensity ${ }^{11}$. Failure to account for climate-attributable capacity reductions during peak demand periods may cause unforeseen electricity shortages.

Currently, the effects of climate change on electric power systems are poorly understood, leaving balancing authorities with little choice but to assess infrastructure reliability based on 
historical climate conditions. Previous research has focused on climate impacts to large nuclearand coal-fired power plants located along major rivers in the Eastern U.S. and Europe ${ }^{1,12}$. While vulnerable, these facilities represent only about $10 \%$ of U.S. generation capacity ${ }^{1}$. By contrast, the Western U.S. (a region of the world that is expected to experience significant climatic and hydrologic changes) relies heavily on alternative generation technologies, with renewables and combustion turbines comprising roughly $56 \%$ of generating capacity ${ }^{13}$. These alternative technologies are expected to represent a greater portion of the future electricity grid ${ }^{14}$. To date, there has been no comprehensive effort to assess the impacts of climate change on a region's overall generation portfolio. Thus, it has not been possible to gauge the effects of climate change on electricity reliability at the grid level. Nor has it been possible to assess how investments in certain generation technologies and transmission infrastructure may increase the resilience of regional power systems.

We assess future electricity reliability in the Western U.S. by evaluating capacity reductions to 978 vulnerable electric power stations under three carbon emissions scenarios. Our study focuses on the power service region of the Western Electricity Coordinating Council (WECC), which currently supplies about $200 \mathrm{GW}$ of summertime generating capacity ${ }^{13}$. WECC encompasses 14 states in the Western U.S., and is electrically autonomous during normal operating conditions ${ }^{15,16}$, allowing conclusions to be drawn about network reliability. To quantify climate-attributable reductions in generating capacity, we isolate vulnerable facilities based on generation technology and cooling water source, identify climatic and hydrologic factors that impair power generation, produce daily simulations of hydro-climatic parameters using a physically-based modeling system, and relate these parameters to achievable capacity at each facility using a mass and energy balance-based approach.

The Western power grid employs a diverse array of generation technologies, each of which is vulnerable to different climatic and hydrologic factors. We investigate five generation 
technologies: steam turbine, combustion turbine, hydroelectric, wind turbine and photovoltaic.

For steam turbine facilities (i.e. "base-load" coal and nuclear power plants), generating capacity is constrained by available streamflow, with cooling water demands being dictated by the enthalpy of air and water entering the cooling system ${ }^{5}$. Combustion turbines and photovoltaic cells experience capacity reductions with increasing air temperatures ${ }^{4,6}$. For hydroelectric facilities, generating capacity is constrained by available streamflow ${ }^{2}$. Wind turbine performance depends on wind speed and air density ${ }^{7}$. In all, six parameters are required to assess impacts on power generation: (i) streamflow, (ii) stream temperature, (iii) air temperature, (iv) vapor pressure, (v) wind speed and (vi) air density. For turbine-based technologies, we apply energy and mass balances to the generator and cooling system to relate achievable capacity to hydro-climatic parameters. For photovoltaic cells, an empirical approach is used. Equations relating generation capacity to hydro-climatic factors can be found in Supplementary Section S2.1. Impacts to existing facilities are considered to be representative of future impacts, given that base-load coal, nuclear and gas facilities are expected to retain $85 \%$ of their capacity by 2040 , and no cumulative retirements are expected for combustion turbine or renewable generation sources ${ }^{14}$. We evaluate impacts to generating capacity at peak load conditions, because this is when power systems are likely to experience the greatest strain (see Supplementary Section S5.1). Under these conditions, both "base load" and "peaking" generation sources are likely to be deployed, meaning that impacts to either generation mode will affect overall electricity reliability.

Hydro-climatic parameters are modeled at a daily time step for both the historical period (1949-2010) and the future period (2010-2060) at a spatial resolution of 1/8-degree, using the Variable Infiltration Capacity (VIC) hydrological model ${ }^{17,18}$, and a semi-Lagrangian stream temperature mode ${ }^{19}$ (see Supplementary Section S2.2). We force the modeling system with gridded observed meteorological data for the historical period ${ }^{20}$, and downscaled forcings from two global climate models (GCMs) for the future period ${ }^{21}$. To capture a range of possible futures, 
we use the A2, A1B and B1 emissions scenarios proposed by the Intergovernmental Panel on Climate Change. These scenarios place bounds on anthropogenic warming, based on divergent trends in carbon emissions. Variations between GCM models represent the primary source of uncertainty for this study, and are therefore incorporated into the results. Secondary sources of uncertainty_including environmental flow requirements and unreported plant specificationsare explored and quantified in Supplementary Section S3.

By mid-century (2040-2060), climate change may reduce average summertime generating capacity by $1.0-2.7 \mathrm{GW}$, with potentially disruptive impacts occurring in California and the desert Southwest. Vulnerable facilities account for $46 \%$ of existing capacity in the WECC region, and among individual facilities, impacts range from a $4 \%$ increase in capacity to a $14 \%$ decrease in capacity. Fig. 1 shows potential impacts to individual facilities, while Fig. 2 shows annualized power generation curves for representative Southwestern and Northwestern regions. Generating capacity decreases for all hydrologic regions considered except the Pacific Northwest (a region expected to receive more precipitation ${ }^{21}$ ), with the greatest impacts occurring in the desert Southwest (a region expected to experience higher temperatures and less rainfall ${ }^{21}$ ). For the California and Colorado river basins, climate change may reduce summertime capacity by 2.0 $5.2 \%$ in an average year. These reductions are mainly attributable to thermoelectric facilities, for which generating capacity is linked to air temperature and available streamflow. For the Pacific Northwest, where hydroelectric power makes up a majority of generating capacity, no relationship between climate change and generation capacity is observed. These findings suggest that transmission infrastructure may play a greater role in ensuring electricity reliability as traditional thermoelectric capacity is more frequently disrupted by extreme heat and drought (see Supplementary Note). Strengthening transmission capacity between Northern and Southern regions may help Southern states manage demand during a drought event, without significantly compromising power reliability in the North. 
Generation portfolio plays a dominant role in determining a region's climate resilience, with some generation technologies being much more "climate-proof" than others. Fig. 3 compares impacts between two conventional technologies and two renewable technologies over the next half-century. Thermoelectric technologies (steam turbine and combustion turbine) suffer the largest climate-attributable capacity reductions - about 1.6-3.0\% for vulnerable facilities by mid-century. Of these technologies, combustion turbines show the most consistent capacity reductions on a year-to-year basis, with average summertime losses of 1.4-3.5\% relative to the historical period. On the other hand, base-load steam turbines are more likely to suffer extreme capacity reductions as a result of drought events. The average 10-year reduction in summertime capacity for steam turbine facilities is expected to increase from $2.5 \%$ under the historical period to $7.4-9.5 \%$ by mid-century. Steam turbine facilities are susceptible to extreme capacity reductions because they are constrained by available streamflow (which may vary by orders of magnitude at a given station), whereas combustion turbines are primarily constrained by air temperature (which resides within a relatively limited range). Compared to conventional thermoelectric technologies, renewables are more resilient to the effects of climate changehowever, impacts to these generation sources are also more uncertain. Utility-scale photovoltaics may experience summertime capacity reductions of $0.7-1.7 \%$ due to higher air temperatures; however, capacity reductions due to changes in incident solar radiation are difficult to estimate reliably. Climate change may slightly increase wind turbine performance due to lower average atmospheric humidity; however, forecasts of wind speed and air density are also uncertain (see Supplementary Section S2.1.4). When the entire WECC region is considered, hydroelectric facilities do not show reductions in average generating capacity. However, uncertainty with respect to reservoir operations and projected water demand limit projections of hydroelectric capacity to an annual timescale. Our results show that an over-reliance on traditional thermoelectric generation may result in unforeseen constraints to generating capacity. Despite the uncertainties inherent in projecting renewable generation potential, renewables are generally less 
susceptible to the effects of climate change, meaning that increased adoption of renewables may not only help reduce greenhouse gas emissions - it may also contribute to a more climateresistant power infrastructure.

In projecting future impacts to electricity supply, major sources of uncertaintyincluding GCM model variability, uncertain model parameters, and future technological change - must be taken into account. While these uncertainties may affect the degree to which climate change impinges on electricity supply, they are unlikely to result in a scenario where generating capacity is not reduced. To determine whether projected impacts are a result of GCM model variability, we test for the statistical significance of our results using the Wilcoxon ranksum method (see Supplementary Section S3.3), and find that there is a significant difference ( $\mathrm{p}$ 0.001 ) in generation capacity between the historical and future periods for all emissions scenarios. Accounting for sources of parameter uncertainty—including unreported plant specifications and environmental flow requirements - results in a slightly wider range of impacts, with average summertime capacity reductions varying from $0.9-4.4 \%$ and extreme reductions varying from 5.9-12\%. Technological change represents an additional source of uncertainty, because increases to power plant efficiency may potentially offset capacity reductions. However, climate impacts may also be compounded by long-term efficiency losses — due to equipment degradation, increased cycling, and utilization of lower quality fuels. We find that potential increases to efficiency are of roughly the same magnitude as potential efficiency decreases, with historical records showing slight decreases in power plant efficiency over time (see Supplementary Section S5.2).

Even in an average year, climate change is expected to have significant impacts on electricity generation capacity; however, the most serious constraints to electricity supply will likely result from extreme drought events. By mid-century, a ten-year drought event may reduce summertime capacity by 6.6-8.0 GW (3-4\% of existing WECC capacity). Power providers 
typically characterize vulnerability in terms of "planning reserve margin" (PRM), which represents the percent of electricity supply "left over" after meeting demand. While PRM is not directly used to predict the incidence of blackouts, brownouts or electricity price increases, it is widely used as a first-order estimate of electricity supply adequacy. WECC anticipates a PRM of $18 \%$ for the year $2023^{22}$. However, PRM does not explicitly account for the effects of climate change, meaning that current forecasts could be overly optimistic. Based on anticipated impacts to existing vulnerable capacity, PRM could be reduced from $18 \%$ to $14 \%$ during a future ten-year drought event. This estimate does not account for vulnerabilities in planned capacity additions. Generating capacity is expected to reach $273 \mathrm{GW}$ by 2040, with combustion turbines and renewables accounting for the majority of planned additions- $-41 \%$ and $53 \%$, respectively ${ }^{14}$. Assuming that impacts to planned capacity are similar to average impacts on existing capacity, planned additions could experience capacity reductions of 1.8-2.5 GW under a ten-year event. This means that in the case of a ten-year drought, power providers could be overestimating PRM by as much as $20-25 \%$. Failure to account for climate-driven capacity reductions could result in periods of constrained electricity supply. Currently, power providers do not account for climate impacts in their development plans, meaning that they could be significantly overestimating their ability to meet future electricity needs. Given that the West is expected to experience greater electricity demand due to rapid population growth and elevated air temperatures, the WECC grid will likely be operating closer to the margin for longer periods of time. Under these constraints, greater efforts must be made to "climate-proof" our power grid—by strengthening transmission capacity, encouraging conservation strategies, investing in more resilient renewable energy sources, and accounting for local climatic constraints when siting new generating facilities. 


\section{References:}

1. Van Vliet M. T. H. et al., Vulnerability of US and European electricity supply to climate change. Nature Climate Change 2, 2, 676-681 (2012).

2. Harto, C.B. \& Yan, Y.E. "Analysis of Drought Impacts on Electricity Production in the Western and Texas Interconnections of the United States" (Environmental Science Division, Argonne National Laboratory, 2011).

3. Kimmell, T. A. \& Veil, J. A. "Impact of Drought on US Steam Electric Power Plant Cooling Water Intakes and Related Water Resource Management Issues” (National Energy Technology Laboratory, Tech. Rep. DOE/NETL-2009/1364, 2009).

4. Sathaye, J. et al., "Estimating risk to California energy infrastructure from projected climate change" (California Energy Commission, Pub. Number: CEC-500-2012-057, 2012).

5. Rutberg, M. J. Modeling water use at thermoelectric power plants, MS Thesis, Massachusetts Institute of Technology (2003).

6. Dubey, S., Sarvaiya, J. N., \& Seshadri, B. Temperature dependent photovoltaic (PV) efficiency and its effect on PV production in the world—a review. Energy Procedia 33, $311-321$ (2013).

7. Royal Academy of Engineering, "Wind Turbine Power Calculations" (London, United Kingdom, https://www.raeng.org.uk/education/diploma/maths/pdf/exemplars_advanced/23_Wind_ Turbine.pdf).

8. Union of Concerned Scientists, "Rising temperatures undermine nuclear power's promise" (Union of Concerned Scientists backgrounder, Washington, DC, August 23, 2007). 
9. "Guide to Tools and Principles for a Dry Year Strategy" (Bonneville Power Administration, 2002; http://www.bpa.gov/power/pgp/dryyear/082002_Draft_Guide.pdf).

10. Operating Experience with Nuclear Power Stations in Member States in 2003 (International Atomic Energy Agency, STI/PUB/1219, Vienna, 2004).

11. Climate Change 2007: Impacts, Adaptation and Vulnerability (Intergovernmental Panel on Climate Change, Cambridge University Press, Cambridge, 2008).

12. Koch, H., \& Vögele, S. Dynamic modelling of water demand, water availability, and adaptation strategies for power plants to global change. Ecological Economics 68, 20312039 (2009).

13. U.S. Energy Information Administration. EIA Form 860. Detailed Data, Year 2012 (www.eia.gov/electricity/data/eia860/).

14. U.S. Energy Information Administration. Annual Energy Outlook 2014 Data Tables. Electric Power Projections by Electricity Market Module Region - Western Electricity Coordinating Council, Tables 55.19-22 (www.eia.gov/forecasts/aeo/data.cfm).

15. “NERC Reliability FAC-010-1, FAC-011-1: Determine Facility Ratings, System Operating Limit and Transfer Capabilities" (Western Electricity Coordinating Council, 2006; http://www.nerc.com/pa/Stand/Determine\%20Facility\%20Ratings\%20Operating\%20Lim its\%20and\%20Tr/WECC_Support_for_Reg_Diff_revised_05Sep06.pdf).

16. "Learn More About Interconnections" (U.S. Department of Energy; energy.gov/oe/services/electricity-policy-coordination-and-implementation/transmissionplanning/recovery-act-0).

17. Liang, X., Lettenmaier, D. P., Wood, E. F., \& Burges, S. J. A simple hydrologically based model of land-surface water and energy fluxes for general-circulation models. Journal of Geophysical Research-Atmospheres 99, 14415-14428 (1994). 
18. Lohmann, D., Raschke, E., Nijssen, B., \& Lettenmaier, D. P. Regional scale hydrology: I. Formulation of the VIC-2L model coupled to a routing model. Hydrological Sciences Journal 43, 131-141 (1998).

19. Yearsley, J. R. A semi-Lagrangian water temperature model for advection-dominated river systems. Water Resources Research 45, W12405 (2009).

20. Maurer, E. P., Wood, A. W., Adam, J. C., Lettenmaier, D.P, \& Nijssen, B. A long-term hydrologically-based data set of land surface fluxes and states for the conterminous United States, J. Climate 15, 3237-3251 (2002).

21. "Downscaled CMIP3 and CMIP5 Climate and Hydrology Projections: Release of Downscaled CMIP5 Climate Projections, Comparison with preceding Information, and Summary of User Needs" (U.S. Department of the Interior, Bureau of Reclamation, Technical Services Center, Denver, Colorado, 2013).

22. 2013 Long-Term Reliability Assessment (North American Electric Reliability Corporation, 2013; http://www.nerc.com/pa/RAPA/ra/Reliability\%20Assessments\%20DL/2013_LTRA_FIN AL.pdf).

\section{Acknowledgements:}

This material is based upon work supported by the National Science Foundation (grant nos. IMEE 1335556, IMEE 1335640, WSC 1360509, RIPS 1441352, and BCS 102686).

\section{Author contributions:}

M.D.B. and M.V.C. designed the study. M.D.B. performed all analyses and collaborated with M.V.C. to interpret the results and draft the manuscript. 


\section{Additional Information:}

The authors declare no competing financial interests.

\section{Figure Captions:}

Fig. 1: Average reductions in summertime capacity by mid-century (2040-2060) for vulnerable facilities in the WECC region. The map (right) shows average reductions across all model/scenario runs (about $1.8 \mathrm{GW}$ in total). The column chart (top-left) shows the range of total capacity reductions between global climate models (UKMO and ECHAM) and emissions scenarios (A1B, A2 and B1).

Fig. 2: Average annualized power generation capacity for representative hydrologic regions. The historical line (black) shows average daily useable capacity for 1949-2010. Red, yellow and blue lines show average useable capacity for the A1B, A2, and B1 scenarios at mid-century (20402060). Grey areas represent the range of uncertainty between the most adverse and least adverse model/scenario runs. The Colorado River Basin (right), shows greater average capacity reductions than the Pacific Northwest (left).

Fig. 3: Summertime power generation capacity for representative generation technologies from 1949-2060. Conventional thermoelectric generation technologies (steam turbine and combustion turbine) are shown on the left, while renewable technologies (hydropower and solar photovoltaic power) are shown on the right. The historical line (black) shows average summertime useable capacity for 1949-2010. Red, yellow and blue lines show average summertime useable capacity for the A1B, A2, and B1 scenarios at mid-century (2040-2060). Grey areas represent the range of uncertainty between the most adverse and least adverse model/scenario runs. 